\title{
An urgent priority: Child and adolescent health and quality of life
}

The essential guidelines for these considerations are basically intended to help find viable approaches to the difficult situation that millions of children and adolescents are facing nowadays in Argentina.

My motivation to offer some suggestions was prompted by the urge to share my 62 years of professional pediatric experience in public and private health care settings, university and community teaching, and clinical and psychosocial research. I was able to access the different hierarchical levels after passing the corresponding competitive examinations; a remarkable privilege that I am always thankful for.

It is a fitting moment to remember some emblematic figures who taught me to consider child and adolescent health and quality of life from a comprehensive perspective and as an unavoidable reality. Among them, I would like to single out Juan Pedro Garrahan, an eminent pediatrician and prominent author of several publications; Florencio Escardó, a key figure in the history of Argentine pediatrics; and Carlos Arturo Gianantonio, undoubtedly the greatest master of this specialty, full of moral values and extraordinary virtues of medical wisdom.

From La Plata, the following figures certainly deserve to be remembered: Noel Humberto Sbarra, a physician with deep democratic convictions, an important public health officer, and a pioneer in the comprehensive care and wellbeing of abandoned children, work he undertook during many years in Casa Cuna e Instituto de Puericultura, which is now a hospital carrying his name; Juan Vicente Climent, a professional tirelessly dedicated to the care of newborns and infants with severe conditions, someone who did not care about pre-set working hours, and a true example of diligence for the healing of children's illnesses. Abraham Rahman, a teacher by vocation and attitude, who transformed teaching into a humanistic mission at the service of trainees in this difficult profession: the most salient aspect of his approach to child and adolescent health care was being the first to consider emotional and psychological problems as factors negatively affecting the quality of life.

In relation to Health Ministry officials who, to my understanding, developed policies in line with the urgencies and needs of children and adolescents, I would like to mention Carlos Bocalandro, Osvaldo Mammoni, Floreal Ferrara, Herminio Zatti, and Ismael Pasaglia.

In this brief summary, I cannot fail to mention so many professionals from various disciplines, workers from different occupational groups, as well as members from community organizations (voluntary service, cooperative associations) which, with their daily work and commitment, have helped to care for children and adolescents, cure them, look after them, accompany them, play with them, and cooperate in such complex moments, when they are suffering from health problems. Nevertheless, these efforts are not enough to alleviate such dire circumstances. There is uncertainty, a feeling of fear, and distress due to a situation that has been unresolved for so long, which has currently worsened. As a matter of fact, according to the National Statistics and Censuses Institute of Argentina (Instituto Nacional de Estadísticas y Censos, INDEC), in the last quarter, poverty affected $40.9 \%$ of the population, but this figure is way more alarming if we take into account that $56.3 \%$ of this group is 0-14 years old. If we also consider the violation of basic rights, multiple socioeconomic inequalities, family disorganization, poor psycho-affective stimulation, elevated school dropout rates, growing illiteracy, low levels of formal education among parents, few health check-ups, incomplete immunization schedules, substandard and overcrowded housing conditions without basic sanitation, child labor in unhealthy conditions, maltreatment and violence by adults or peers, child and adolescent sexual abuse, limited game sharing, loneliness, parents out of work or with informal labor, addictions, TV and computer overuse, and many other vulnerability factors that have an unfavorable impact on a good quality of life, we realize that addressing these real scourges is a titanic and pressing task that cannot be avoided. Not doing so would entail going backwards toward complete dehumanization.

This aspiration aims that all adults, whatever our social role, begin to understand that it is an ethical, social, and historical responsibility to understand and protect all children and adolescents without any type of discrimination, if we want and hope for a better future.

It will be necessary to implement preventive, 
non-homogeneous health policies, adapted to local, regional, provincial, and national needs, which contribute to eradicate inequalities currently affecting this population. It is critical to maintain child and adolescent full health or recover it if it has been lost. To that end, government budget investment financing all health care requirements is critical, and it should be maintained in the future and forever. It is also necessary to warrant a decent living wage for all health care workers, without exception.

In line with a change in the health care model allowing for an improvement of the sufferings experienced by a large part of the child and adolescent population, I propose some simple actions and strategies that would help in this regard:

- Fully complying with the Convention on the Rights of the Child, which has been introduced into the Argentine National Constitution.

- Warranting access to periodic check-ups for all pregnant women.

- Promoting facility-based, humanized childbirth.

- Controlling newborn infants in a comprehensive manner.

- Encouraging breastfeeding immediately after birth in a systematic fashion.

- Introducing complementary feeding with solid and semi-solid foods at 4-6 months of age while maintaining breastfeeding, if possible.

- Ensuring that all families are able to access the basic basket of healthy foods.

- Controlling anthropometric measurements (weight, height, and head circumference) periodically and creating the corresponding charts.

- Monitoring psychological, motor, and adaptive evolutionary development, and language and personal-social skills.

- Complying with the official immunization schedule for all children and adolescents.

- Organizing interdisciplinary health care teams in every child and adolescent health care facility.

- Offering guidelines on early child development and how to acquire them in all children, including those with different abilities.
- Diagnosing prevalent conditions with timely, anticipatory, and preventive criteria.

- Making the joint hospitalization of children with their mother or father mandatory.

- Preventing harmful work at ages not allowed by law.

- Prioritizing primary health care, which is the entry door to the health care system.

- Warranting accessibility, equity, and quality in the provision of services.

- Extending outpatient care hours in public and private settings.

- Reorganizing health care facilities according to levels of growing complexity.

- Enabling mechanisms for effective and efficient referrals.

- Offering appropriate sexual education in all sectors of education.

- Fostering permanent, tri-generational, emotional bonds among children and adolescents and their parents and grandparents.

- Avoiding the irrational use of technology in disease diagnosis and therapeutic futility.

- Promoting healthy work environments based on listening, consensus, and friendly communication within the health care staff, both in public and private facilities.

Please note that not everyone may agree with the above-mentioned suggestions. Democratic dissent is welcome and will surely make it possible to consider other options. Let us join the efforts of families, communities, facilities, and the State, and these and other proposals will certainly materialize one urgent priority: ensuring child and adolescent health and quality of life.

Roberto J. M. Mateos, M.D. Former Professor of Pediatrics, Universidad Nacional de La Plata, Buenos Aires, Argentina.

http: / / dx.doi.org/10.5546/ aap.2021.eng.148

To cite: Mateos RJM. An urgent priority: Child and adolescent health and quality of life. Arch Argent Pediatr 2021;119(3):148-149. 


\section{Impact on the selection process of new neonatology residents due to the COVID-19 pandemic}

The SARS-CoV-2 pandemic we are now experiencing has radically transformed the usual development of medicine and, therefore, routine practice. We changed from a close personal contact to a setting of extreme protection, which is uncomfortable but necessary. Several sectors of society have been affected, and one of them has been medical academic coexistence, where sessions, patient handoff, congresses, and conferences are no longer the way they used to be.

Medical education has been forced to adapt to the high health care demand resulting from this contingency and to the need to continue with academic programs. For this reason, the education process has become an active, dynamic, and predominately virtual agent, unlike what has happened with health care activities. $^{1}$

The preparation of new physicians and specialists is not exempt from this new normal; young physicians who should be learning how to manage different diseases have been forced to devote $100 \%$ of their time to caring for SARS$\mathrm{CoV}-2$ patients and related complications.

As evidenced, hospitals take part in the education process of physicians on the different areas of medicine. In spite of the pandemic, society still requires support from other medical departments that are not directly or indirectly affected by the pandemic. This has called for their ongoing operations and, in some contexts, for a work overload due to other health care centers shutting down to become COVID-19 hospitals. ${ }^{2}$

All these physicians go through a strict selection process to get admitted to each specialty program; they have to pass tests on medical and general knowledge, psychometric tests, and have interviews with the professors of their chosen specialty, who have adapted to safeguard the health and well-being of all those involved in these activities.
A personal interview has always served as an instrument to identify candidates to the different specialties; their personality, behavior, and attitude towards certain problems have all been part of the selection process. During the pandemic, we have had to migrate to virtual interviews, which lack the personal interaction, and candidates show different reactions when sitting in front of their computer or tablet camera, leading to a lower extent of visual tension and inquisitive approach from some interviewers; therefore, they end up missing certain details in relation to candidates.

However, not everything is bad news; online interviews have expanded the possibility of talking to candidates from all over the world thanks to online connections and also to schedule interviews on the same day because candidates do not need to travel. In relation to interviewers, now there is also a better chance of having several people conducting the interviews across different locations.

Only time will tell the consequences of the new digital alternatives developed in relation to medical education and their impact on clinical practice and community health. Some medical specialties have even interrupted their activities to care for patients affected by the SARS-CoV-2 pandemic.

Bronson Osorio Martínez M.D. ${ }^{a}$ Jorge A. Martínez Cardona M.D. ${ }^{b}$

a. Pediatrician and Neonatologist, Director of the Neonatology Program, Multicenter Program of Medical Specialties, Tecnologico de Monterrey. Monterrey, Nuevo León, Mexico.

b. Pediatrician, Neonatology Resident, Multicenter Program of Medical Specialties, Tecnologico de Monterrey. Monterrey, Nuevo León, Mexico.

E-mail address:

Jorge A. Martínez Cardona: jorge.mtzcardona@gmail.com

http: / / dx.doi.org/10.5546/ aap.2021.eng.150

To cite: Osorio Martínez B, Martínez Cardona JA. Impact on the selection process of new neonatology residents due to the COVID-19 pandemic. Arch Argent Pediatr 2021;119(3):150-151. 


\section{REFERENCES}

1. RoseS. Medical StudentEducation in the Time of COVID-19. JAMA. 2020; 323(21):2131-2.
2. Ayanian JZ, Weissman JS. Teaching hospitals and quality of care: a review of the literature. Milbank Q. 2002; 80(3): 569-93, v. 